\title{
Perceptions on gender norms and gender based violence among women in a rural community in Sri Lanka: Findings from a cross sectional study
}

\author{
HMTP Herath*, JEMSS Jayarathna** \\ * Department of Primary Health Care, Eastern University, Sri Lanka \\ **National Child Protection Authority \\ DOI: $10.29322 /$ IJSRP.10.05.2020.p10149 \\ http://dx.doi.org/10.29322/IJSRP.10.05.2020.p10149
}

\begin{abstract}
Studies around the world have found that gender based violence is most common where gender roles are rigidly defined and enforced. Evidence also suggests that justifications for violence frequently evolve from gender norms. Based on this, this study was aimed to identify the perceptions on gender norms and gender based violence among women in a rural community in Sri Lanka.A cross sectional study was conducted by recruiting seventy four women and a same number of families, randomly. Six gender norms that were assumed to have a commitment to create gender based violence were assessed using five-point likert type scales and perceptions on violence were assessed by using four statements on violence positive attitudes included in a self-administered questionnaire. Majority (91.5\%) of the women agreed that responsibility for nurturing and caring children is mostly lies with women than men and household activities should be known by women than men.Lowest acceptance (22.1\%) reported for the norm 'consuming alcohol and tobacco is a masculine thing' among women. High number of women (81.9\%) perceives that behaving violently by men can be justified if the violence act occurs due to a failure of women's duties. Majority of the families (91.6\%) accept that 'responsibility for nurturing and caring children is mostly lies with woman than man.'More than 50\% of the women showed an agreement on five norms out of the six norms that were assessed during the study. Majority of them also possess violence supportive attitudes. Most of the families believe that child care is a responsibility of women. Therefore these prominent norms and violence supportive attitudes need to be considered in designing interventions targets to prevent the gender based violence among a rural community.
\end{abstract}

Index Terms- Gender based violence, Gender norms, Gender stereotyping, Women

\section{INTRODUCTION}

Gender Based Violence (GBV) has become a leading global public health issue [1-3]. According to past literature, gender inequality and discriminationare defined as the root causes of GBV [4]. Evidence also suggests that, gender inequalities increase the possibilities of violence by men against women and also hinder the opportunities for protection [5]. Further, studies had shown that GBV is interwoven with set of gender norms that prescribe men and women's roles in society via the process of gender stereotyping [4-6].

Globally, gender stereotyping has become a leading agent of deterioration of both women and men's health and wellbeing [7]. According to global data, adherence to gender norms will more likely to result in having used physical violence against women \& between men, to have had a sexually transmitted infection, to have been arrested, to use substances, poor contraceptive use, poor parenting practices and health-seeking behaviours among men [8]. Similarly, having GBV supportive attitudes leads behavioral intentions on using violence irrespective of choosing healthy problem solving methods [9-11]. 
Because of the utmost importance of GBV as a public health issue, gender becomes forefront in international and national interventions for achieve gender equity and combat against GBV [12]. Evidence points out that, not only individual \& community attitudes and norms have a role in determining the issue, but also social reproduction through gender stereotyping agents also have tremendous implications [13]. Although, gender stereotyping is often overlooked by many interventions, it should be captured a same priority like gender norms to tackle GBV [14]. Furthermore, there is a dearth of scientific research evidence on prevalence of gender norms and supportive perceptions on GBV. As well as evaluating intervention effects on these areas are often ignored by majority of past studies in the globe [15]. In Sri Lanka, there is paucity of scientific evidence in peer reviewed literature on gender matters which hinder the capacities of program planners and policy makers to design effective measures [16].

This article describes prevalence of perceptions of gender norms and GBV among a rural community in Sri Lanka, particularly as for a screening of the community as the first step in a pilot study in which an intervention would be designed to change the identified gender norms and GBV supportive attitudes. These norms represent most prominent gender norms which have profound influence to occur a violence act by a male partner identified by the global literature [17]. So, this study would meet the demand of identifying the prevalence of violence triggering norms in the Sri Lankan context. Moreover, Sri Lankan health system can design locally relevant measures against GBV by moving a step forward by obtaining support of this data.

\section{MATERIALS AND METHODS}

Study design and setting

This study was the first component of a larger pilot study which targeted to design an intervention to change the acceptance on gender norms and GBV among families who have at least one under five year old child. A cross sectional study was carried out as the first component from January 2011 to December 2011 in the Anuradhapura district of Northern Province of Sri Lanka.

Study population and sample

In Sri Lanka, a growth monitoring program will be conducted by the health ministry in each village for children under five years and this weight measuring post has named as the Weighing Post (WP). On the weighing day all the mothers will participate at a stipulated time. By considering the feasibility of gathering the community for the intervention, families who have at least one under five year old child were considered as the study population. For the intervention component, two Public Health Midwifery (PHM) areas were selected from Anuradhapura district by means of similar socioeconomic background but with an approximate distance in order to select an intervention and a control group. Out of the WPs in two PHM areas, two WPs were selected by using simple random sampling method. So, all the women (74) and families (74) of the intervention (women=42, families-42) and control (women=32, families=32) groups were considered as the sample for the cross sectional survey.

\section{Data Collection}

The data on perceptions on gender and GBV were collected from the women who participated for the WP at their home following a notice regarding the data collection which was given prior visiting the home. Two attempts were taken to meet the mother. A household detail sheet was prepared and a random number was generated to select a member from the family to gather data on family perception on gender. There was two attempts to meet the generated random number if these two attempts were unsuccessful the generated random number was refused. Another random number was generated to these occasions. 
Data collection instruments

A pre-tested validated interviewer administrated questionnaire was used for data collection. Questionnaire was developed to suit to Sri Lankan context by in cooperating experts views on local gender norms and by referring to past literature to detect prominent gender norms and perceptions on GBV. This study assessed the perceptions on gender roles in terms of six selected gender norms and perceptions on GBV in terms of 4 statements regarding violence supportive attitudes. For each norm women could respond for a five point likert type scale ranging from totally agree, agree, can't say, disagree to totally disagree whereasa scale ranging from 100\%, $75 \%, 50 \%, 25 \%$ to $0 \%$ were used for the families.Demographic and socio-economic data (age, level of education, employment status of the both wife and husband) were also obtained.

Data analysis and ethical considerations

Descriptive statics were used to describe the findings and data were analyzed by using the Statistical Package for Social Sciences (SPSS) statistical software. Ethical clearance was obtained from the Ethical Review Board of the Faculty of Medicine, Rajarata University of Sri Lanka. Informed written consent for participation was soughed prior to recruitment to the study. Specific measures were taken during the study to improve the confidentiality of data.

\section{FINDINGS}

\section{Socio economic and demographic characteristics of the sample}

As shown in table 1, the majority of women (34.7\%) belong to the 23-26 age groups. More than 72\% of women are housewives. More than $50 \%$ of women educated up to ordinary levels. More than $50 \%$ of the husbands do occupations in forces.

Table 1: Socio economic and demographic characteristics of the sample

\begin{tabular}{|c|c|c|}
\hline Criteria & Frequency $\mathbf{N}$ & Percentage \% \\
\hline \multicolumn{3}{|l|}{ Age range of the women } \\
\hline $19-22$ & 07 & 9.7 \\
\hline $23-26$ & 25 & 34.7 \\
\hline $27-30$ & 23 & 31.9 \\
\hline $31-34$ & 13 & 18.1 \\
\hline 35 and above & 04 & 5.6 \\
\hline Total & 72 & 100.0 \\
\hline \multicolumn{3}{|l|}{ Occupation of the women } \\
\hline Housewife & 56 & 77.8 \\
\hline Farmer & 15 & 20.8 \\
\hline Teacher & 01 & 5.6 \\
\hline Total & 72 & 100.0 \\
\hline \multicolumn{3}{|c|}{ Education level of the women } \\
\hline Below grade 8 & 01 & 1.4 \\
\hline pass 8 & 12 & 16.7 \\
\hline
\end{tabular}




\begin{tabular}{|l|c|c|}
\hline pass O/L & $\mathbf{4 0}$ & $\mathbf{5 5 . 5}$ \\
\hline pass A/L & 19 & 26.4 \\
\hline Total & $\mathbf{7 2}$ & $\mathbf{1 0 0 . 0}$ \\
\hline Occupation of the women's husbands & 39 & $\mathbf{5 4 . 2}$ \\
\hline Forces & $\mathbf{1 8}$ & $\mathbf{2 5 . 0}$ \\
\hline Farmer & $\mathbf{0 1}$ & $\mathbf{1 . 4}$ \\
\hline Teacher & $\mathbf{0 3}$ & $\mathbf{4 . 2}$ \\
\hline Government office workers & $\mathbf{0 3}$ & $\mathbf{4 . 2}$ \\
\hline Carpenters & $\mathbf{0 6}$ & $\mathbf{8 . 3}$ \\
\hline police or civil security & $\mathbf{0 2}$ & $\mathbf{2 . 7}$ \\
\hline No job & $\mathbf{7 2}$ & $\mathbf{1 0 0 . 0}$ \\
\hline Total & & \\
\hline
\end{tabular}

\section{Perceptions of gender role among women}

As shown in the table 2, majority of the women 66 (91.5\%) agree on the norms 'women are more responsible on nurturing and caring child than men' and 'Household activities should be known by women than men'. Majority of the women 55 (76.3\%) disagreed on the norm 'consuming alcohol and tobacco is considered as a masculine behavior'.

Table 2: Perception of gender role among women

\begin{tabular}{|c|c|c|}
\hline Gender norm & Frequency $\mathbf{N}$ & Percentage $\%$ \\
\hline \multicolumn{3}{|c|}{ Responsibility for nurturing and caring children is mostly lies with women than men } \\
\hline Totally agree & 55 & 76.3 \\
\hline Agree & 11 & 15.2 \\
\hline Can’t say & $\mathbf{0 0}$ & $\mathbf{0}$ \\
\hline Disagree & $\mathbf{0 2}$ & 2.7 \\
\hline Totally disagree & 04 & 5.5 \\
\hline Total & 72 & 100.0 \\
\hline \multicolumn{3}{|c|}{ Women are considered as more frugal than men } \\
\hline Totally agree & 53 & 73.6 \\
\hline Agree & 18 & 25 \\
\hline Can't say & $\mathbf{0}$ & $\mathbf{0}$ \\
\hline Disagree & $\mathbf{0}$ & $\mathbf{0}$ \\
\hline Totally disagree & 1 & 7.5 \\
\hline Total & 72 & $\mathbf{1 0 0 . 0}$ \\
\hline \multicolumn{3}{|c|}{ Behaving violently in a problem is considered as a masculine behavior } \\
\hline Totally agree & 09 & 12.5 \\
\hline Agree & 44 & 61.1 \\
\hline
\end{tabular}




\begin{tabular}{|c|c|c|}
\hline Can't say & 07 & 9.7 \\
\hline Disagree & $\mathbf{0 8}$ & 11.1 \\
\hline Totally disagree & 04 & 5.5 \\
\hline Total & 72 & $\mathbf{1 0 0 . 0}$ \\
\hline \multicolumn{3}{|c|}{ Household activities should be known by women than men } \\
\hline Totally agree & 47 & 65.2 \\
\hline Agree & 19 & 26.3 \\
\hline Can’t say & $\mathbf{0}$ & $\mathbf{0}$ \\
\hline Disagree & $\mathbf{0 2}$ & 2.7 \\
\hline Totally disagree & 04 & 5.5 \\
\hline Total & 72 & $\mathbf{1 0 0 . 0}$ \\
\hline \multicolumn{3}{|c|}{ Preparation of the meals for the family should be done by women } \\
\hline Totally agree & 31 & 43 \\
\hline Agree & 14 & 19.4 \\
\hline Can't say & 01 & 1.3 \\
\hline Disagree & 13 & 18.0 \\
\hline Totally disagree & 13 & 18.0 \\
\hline Total & 72 & 100.0 \\
\hline \multicolumn{3}{|c|}{ Consuming alcohol and tobacco is considered as a masculine behavior } \\
\hline Totally agree & 04 & 5.5 \\
\hline Agree & 12 & 16.6 \\
\hline Can't say & 01 & 1.3 \\
\hline Disagree & 11 & 15.2 \\
\hline Totally disagree & 44 & 61.1 \\
\hline Total & 72 & 100.0 \\
\hline
\end{tabular}

\section{Perceptions of GBV among women}

As shown in the table majority of the women 59(81.9\%) are totally agreed on the statement 'males have to behave violently when women can't fulfill her duties and roles'. Further, most of women $58(80.5 \%)$ were also agree on the statement 'males behave violently because they are usually violent than women'. 
Table 3: Perception of GBV among women

\begin{tabular}{|c|c|c|}
\hline Statement & Frequency $\mathbf{N}$ & Percent \% \\
\hline \multicolumn{3}{|c|}{ It is justifiable for a man to behave violently when women are unable to fulfill her duties and roles } \\
\hline Totally agree & 45 & 62.5 \\
\hline Agree & 14 & 19.4 \\
\hline Can’t say & 00 & $\mathbf{0}$ \\
\hline Disagree & $\mathbf{0 8}$ & 11.1 \\
\hline Totally disagree & 05 & 6.9 \\
\hline Total & 72 & 100.0 \\
\hline \multicolumn{3}{|c|}{ Males are behave violently because they are usually violent than women } \\
\hline Totally agree & 35 & 48.6 \\
\hline Agree & 23 & 31.9 \\
\hline Can’t say & $\mathbf{0 0}$ & $\mathbf{0}$ \\
\hline Disagree & 09 & 12.5 \\
\hline Totally disagree & 05 & 6.9 \\
\hline Total & 72 & 100.0 \\
\hline \multicolumn{3}{|c|}{ Men behave violently in a problem because it is a masculine thing } \\
\hline Totally agree & 35 & 48.6 \\
\hline Agree & 20 & 27.7 \\
\hline Can’t say & $\mathbf{0}$ & $\mathbf{0}$ \\
\hline Disagree & 7 & 9.7 \\
\hline Totally disagree & 10 & 13.8 \\
\hline Total & 72 & $\mathbf{1 0 0 . 0}$ \\
\hline \multicolumn{3}{|c|}{ Men behave violently not because to avoid by saying they are weak } \\
\hline Totally agree & 14 & 19.4 \\
\hline Agree & 36 & 50 \\
\hline Can't say & 05 & 6.9 \\
\hline Disagree & 11 & 15.2 \\
\hline Totally disagree & 06 & 8.3 \\
\hline Total & 72 & 100.0 \\
\hline
\end{tabular}

\section{Attitudes towards gender norms in families}

As shown in the table 4, majority of families 66(91.6\%) agree on the norm 'responsibility for nurturing and caring children is mostly lies with women than men'. Similarly, most of the families $65(90.2 \%)$ agree that women are considered more frugal than men. 
Table 4: Attitudes towards gender roles in families

\begin{tabular}{|c|c|c|}
\hline Statement & Frequency $\mathbf{N}$ & Percentage \% \\
\hline \multicolumn{3}{|c|}{ Responsibility for nurturing and caring children is mostly lies with women than men } \\
\hline $100 \%$ think & 35 & 48.6 \\
\hline $75 \%$ think & 31 & 43 \\
\hline $50 \%$ think & 05 & 6.9 \\
\hline $25 \%$ think & 0 & 0 \\
\hline $0 \%$ think & 1 & 1.3 \\
\hline Total & 72 & 100.0 \\
\hline \multicolumn{3}{|c|}{ Women are considered more frugal than men } \\
\hline $100 \%$ think & 38 & 52.7 \\
\hline $75 \%$ think & 27 & 37.5 \\
\hline $50 \%$ think & 06 & 8.3 \\
\hline $25 \%$ think & 0 & 0 \\
\hline $0 \%$ think & 1 & 1.3 \\
\hline Total & 72 & 100.0 \\
\hline \multicolumn{3}{|c|}{ Behaving violently in a problem is considered as a masculine behaviour } \\
\hline $100 \%$ think & 11 & 15.2 \\
\hline $75 \%$ think & 31 & 43 \\
\hline $50 \%$ think & 13 & 18 \\
\hline $25 \%$ think & 13 & 18 \\
\hline $0 \%$ think & 04 & 5.5 \\
\hline Total & 72 & 100.0 \\
\hline \multicolumn{3}{|c|}{ Household activities should be known by women than men } \\
\hline $100 \%$ think & 36 & 50 \\
\hline $75 \%$ think & 23 & 31.9 \\
\hline $50 \%$ think & 07 & 9.7 \\
\hline $25 \%$ think & 02 & 2.7 \\
\hline $0 \%$ think & 04 & 5.5 \\
\hline Total & 72 & 100.0 \\
\hline \multicolumn{3}{|c|}{ Preparation of the meals for the family should be done by the women } \\
\hline $100 \%$ think & 16 & 22.2 \\
\hline $75 \%$ think & 33 & 45.8 \\
\hline $50 \%$ think & 08 & 11.1 \\
\hline $25 \%$ think & 09 & 12.5 \\
\hline $0 \%$ think & 06 & 8.3 \\
\hline Total & 72 & 100.0 \\
\hline
\end{tabular}




\begin{tabular}{|l|c|c|}
\hline \multicolumn{3}{|l|}{ Consuming alcohol and tobacco is considered as a masculine behaviour } \\
\hline $100 \%$ think & 01 & 1.3 \\
\hline $75 \%$ think & 07 & 9.7 \\
\hline $50 \%$ think & 05 & 6.9 \\
\hline $25 \%$ think & 08 & 11.1 \\
\hline $0 \%$ think & 51 & 70.8 \\
\hline Total & 72 & 100.0 \\
\hline
\end{tabular}

\section{DISCUSSION}

Our findings indicate that the norm 'responsibility for nurturing and caring children is mostly lies with women than men' and 'household activities should be known by women than men' is higher among women while most of the family members also perceive the norm 'responsibility for nurturing and caring children is mostly lies with women than men'. Further, majority of the women perceive, violence to women by men can be justifiable, if the violence occurred due to a failure of fulfilling women's roles.

Acceptances on prominent gender norms which 'trigger' violence against women according to past studies were measured by this study. These events represent transgression of dominant gender norms[3]. When considered about the dominant gender norms which trigger violence, among both women and families, there was more than 50\% agreement on five out of six norms that were checked in this study. These acceptances denote the traditional division of work among the male and female in a Sri Lankan context. In Sri Lanka, according to research, exposure to violence is high, when gender norms aren't followed by females [9-11]. Data from this study suggest a strong possibility of violence acts in families due to high prevalence of norms, and in turn propose the need for properly planned interventions. Women are the leading agents of gender stereotyping and knowing their thinking pattern is well proved [7] and in turn an implication for future research.

Though, the current study results are couldn't compare with Sri Lankan studies as lack of scientific evidence, this study can be comparable with other research evidence in the world on incidents which are triggered violence [18, 19]. Moreover, go et al [20] in his study has investigated gender norms in India which had effect on increasing HIV risk. According to this study women may be particularly vulnerable to violence if the gender gaps are high. Authors have described gender norms in different angles but mainly through a qualitative study. How much women have the decision making skill in relation to normal day today activities are not measured by this current study. In contrast, Balk [8] has measured decision making and attitudes related to day today living. He also described associations between several socio economic and demographic factors such as education, working outside of the home, age at first marriage with women's freedom to omit gender norms. As women are the main audience for a planned intervention on changing acceptances of gender norms, this study measured women's acceptances on gender norms only. Men are also an important population group in such interventions as they could utilize as changing agents. This current study hasn't measured men's perceptions on gender norms directly. During the random selection of a family representative there were a men's representation though, it haven't taken in to analysis as this planned intervention focus to empower women. Even though, Pulerwitz and Barker [21] measured men's attitudes on gender norms through a Gender- Equitable men's scale (GEM). Well-designed programs for men are also important to have positive changes of them and according to studies gender transformative interventions are effective as these beyond the individual context [8]. 
Women also possessed positive violence related attitudes. Around $80 \%$ of women perceive, 'it is justifiable to behave violently when women are unable to fulfill her duties and roles'. This is also an important finding because this denotes the thinking pattern of rural women though violence is an issue of them. According to Sri Lankan and worldwide studies rural areas are more prone to occur violence [22]. High prevalence of violence in rural areas may be due to these types of deep rooted gender serotypes. Further, even the impact is on women, women themselves accepting the violence and justifies it by taking the fault as being unable to fulfill socially constructed role, on them. These attitudes should be effectively addressed for a successful GBV prevention intervention and targeting women is also an utmost important measure, because women can play a significant role in changing these perceptions among them or in next generations while stopping being a victim. Keleher [23] is also pointing out targeting women and girls are a sound investment for these kinds of interventional research on GBV prevention. Inequitable gender norms and stereotypes are embedded in different domains. According to past studies gender norms have implications to political, cultural and economic structures and control women's economic power. This low bargaining power could be a vehicle for continuing unequal gender stratifications and women to not to take control over her life [24].

GBV is a complex phenomenon shaped by antecedents operates at different levels and gender plays a foundation role. According to studies, this has important implications for the design of interventions to address GBV [3]. A recent review highlights that, it is easier to increase awareness and modify attitudes than to change violent behavior [22]. Similarly, this study is also dealt with perceptions as the major priority and provide data for further research. Further according to this review community wide interventions are required to prevent violence and these should address social and cultural factors at the community level. According to several studies mobilizing communities targeting both young males and females will be a key in reducing levels of violence $[4,5,22,25]$ through addressing gender norms. This study is also a forefront to design such intervention for Sri Lanka. In Sri Lanka, women who have children under five years are more likely to be enthusiastic on their family wellbeing, therefore, need to ensure the adaptability of current study findings for other women groups in general. Hence this study is checked with a rural setup, applying to an urban setting might need modifications.

Limitations of this study include small sample size; inability to generalize finding to whole district because of the selection of one village with in it and selection of women who have a child under five years as the study population.

Our study raises recommendations for the development of evidence based GBV prevention interventions for a rural Sri Lankan setup. This study can be taken as an evidence for future policy measures that this kind of initiations should be started at grassroots level health centers and grassroots level health officers should take lead in reversing gender norms in the next generation.

\section{CONCLUSION}

With the figures finding out by the study it can conclude that norms such as 'responsibility for nurturing and caring children is mostly lies with women than men' and 'household activities should be known by women than men' are highly prevalent in a rural women's community while most of the family members also perceive 'responsibility for nurturing and caring children is mostly lies with women than men'. Further, majority of the women perceive violence to women by men can be justifiable, if the violence occurred due to a failure of fulfilling women's duties and roles. So, these perceptions should be considered when designing interventions targeting questioning gender norms and GBV. 


\section{ACKNOWLEDGMENT}

Authors would like to thank Regional Director of Health Services, Medical Officer of Health and PHMs in selected areas for providing permission and logistic support. Finally authors also thank women and their families on behalf of participating for this study.

\section{REFERENCES}

1. Chaudhury et al. Possible psychosocial strategies for controlling violence against women. Industrial Psychiatry Journal. 2009; 18:132-134

2. Ellsberg M, Gottmoeller M, Heise L. A global overview of gender-based violence. Int J Gynaecol Obstet. 2002 Sep;78 Suppl 1:S5-14.

3. Ellsberg M, Heise L. Researching Violence against Women: A Practical Guide for Researchers and Activists. 2005 whqlibdoc.who.int/publications/2005/9241546476_eng.pdf [Accessed 25 October 2012]

4. World Health Organization. Violence prevention the evidence: Promoting Gender equality to prevent violence against women. 2009.www.who.int/violence injury prevention/violence/gender.pdf [Accessed 16 October 2012]

5. UNFPA. Programing to address violence against women. 2006. www.unfpa.org/resources/programming-address-violence-against-women [Accessed 13 January 2015]

6. Jay Jewkes RK, Dunkle K, Nduna M, Shai N. Intimate partner violence, relationship power inequity, and incidence of HIV infection in young women in South Africa: a cohort study. Lancet. 2010; 376:41-48.

7. World Health Organization. Gender and health.1998

8. Barker G, Ricardo C, Nascimento M, Olukoya A, Santos C. Questioning gender norms with men to improve health outcomes: evidence of impact. Glob Public Health.. 2010 Sep 1;5(5):539-53.

9. Bott S, Morrison A, Ellsberg M. Preventing and responding to gender-based violence in middle and low-income countries: a global review and analysis.

10. Martin SL, Moracco KE, Garro J, Tsui AO, Kupper LL, Chase JL, Campbell JC. Domestic violence across generations: findings from northern India. International journal of epidemiology. 2002 Jun 1;31(3):560-72.

11. Kim J, Motsei M. "Women enjoy punishment": attitudes and experiences of gender-based violence among PHC nurses in rural South Africa. Social Science \& Medicine. 2002 Apr 30;54(8):1243-54.

12. Krug EG, Mercy JA, Dahlberg LL, Zwi AB. The world report on violence and health. The lancet. 2002 Oct 5;360(9339):1083-8.

13. Russo NF, Pirlott A. Gender-based violence. Annals of the new york academy of sciences. 2006 Nov 1;1087(1):178-205.

14. Whitaker DJ, Morrison S, Lindquist C, Hawkins SR, O'Neil JA, Nesius AM, Mathew A, Reese LR. A critical review of interventions for the primary prevention of perpetration of partner violence. Aggression and Violent Behavior. 2006 Apr 30;11(2):151-66. Whitaker DJ, Morrison S, Lindquist C, Hawkins SR, O'Neil JA, Nesius AM, Mathew A, Reese LR. A critical review of interventions for the primary prevention of perpetration of partner violence. Aggression and Violent Behavior. 2006 Apr 30;11(2):151-66.

15. Jayatilleke AC, Poudel KC, Yasuoka J, Jayatilleke AU, Jimba M. Intimate partner violence in Sri Lanka. Bioscience trends. 2010 Jun 1;4(3).

16. Heise L, Ellsberg M, Gottmoeller M. A global overview of gender-based violence. Int J Gynaecol Obstet.. 2002 Sep 1;78(S1).

17. Pettifor A, Lippman SA, Selin AM, Peacock D, Gottert A, Maman S, Rebombo D, Suchindran CM, Twine R, Lancaster K, Daniel T, Gómez-Olivé FZ, Kahn K, MacPhail C. Cluster randomized-controlled trial of a community mobilization intervention to change gender norms and reduce HIV risk in rural South Africa: study design and intervention. BMC Public Health. 2015; 15:752

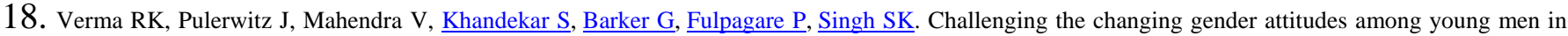
Mumbai, India. Reprod Health Matters. 2006; 14: 135-143.

19. Go VF, Sethulakshmi CJ, Bentley ME, Sivaram S, Srikrishnan AK, Solomon S, Celentano DD. When HIV-prevention messages and gender norms clash: the impact of domestic violence on women's HIV risk in slums of Chennai, India. AIDS and Behavior. 2003 Sep 1;7(3):263-72.

20. Pulerwitz J, Barker G. Measuring attitudes toward gender norms among young men in Brazil: Development and psychometric evaluation of the GEM Scale. Men and Masculinities. 2008 Apr;10(3):322-38.

21. Morrison A, Ellsberg M, Bott S. Addressing Gender-Based Violence: A Critical Review of Interventions The World Bank Research Observer, 2007; 22:1 
22. Keleher H. Changing gendered norms about women and girls at the level of household and community: a review of the evidence. Glob Public Health. 2008;3 Suppl 1:42-57. doi: 10.1080/17441690801892307.

23. Seguino S. PlusÇa Change? 1 evidence on global trends in gender norms and stereotypes. Feminist Economics. 2007 Apr 1;13(2):1-28.

24. Nascimento M. Olukoya A, Ricardo C. Questioning gender norms with men to improve health outcomes: Evidence of impact. Glob Public Health. 2010;5(5):539-53. doi: 10.1080/17441690902942464

\section{AUTHORS}

First Author - HMTP Herath, Lecturer, Department of Primary Health Care, Eastern University, Sri Lanka herathhmtp@gmail.com Second Author - JEMSS Jayarathna, Divisional Child Protection Officer, National Child Protection Authority, Sri Lanka ssjayarathna@gmail.com

Third Author - WMS Fernando, Senior Lecturer, Department of Biological Sciences, Rajarata University of Sri Lanka Fourth Author- D Guruge, Senior Lecturer, Department of Biological Sciences, Rajarata University of Sri Lanka

Correspondence Author - HMTP Herath, Department of Primary Health Care, Eastern University, Sri Lanka herathhmtp@ gmail.com +094 0718175169 